This item was submitted to Loughborough's Research Repository by the author.

Items in Figshare are protected by copyright, with all rights reserved, unless otherwise indicated.

\title{
Multiparameter flow cytometry for the characterization of human embryonic stem cells
}

PLEASE CITE THE PUBLISHED VERSION

http://dx.doi.org/10.1007/s10529-012-1052-y

PUBLISHER

(c) Springer Verlag

VERSION

AM (Accepted Manuscript)

LICENCE

CC BY-NC-ND 4.0

\section{REPOSITORY RECORD}

Brosnan, Kathryn, Andrew Want, Karen Coopman, and Christopher J. Hewitt. 2012. "Multiparameter Flow Cytometry for the Characterization of Human Embryonic Stem Cells". figshare.

https://hdl.handle.net/2134/11056. 
This item was submitted to Loughborough's Institutional Repository (https://dspace.lboro.ac.uk/) by the author and is made available under the following Creative Commons Licence conditions.

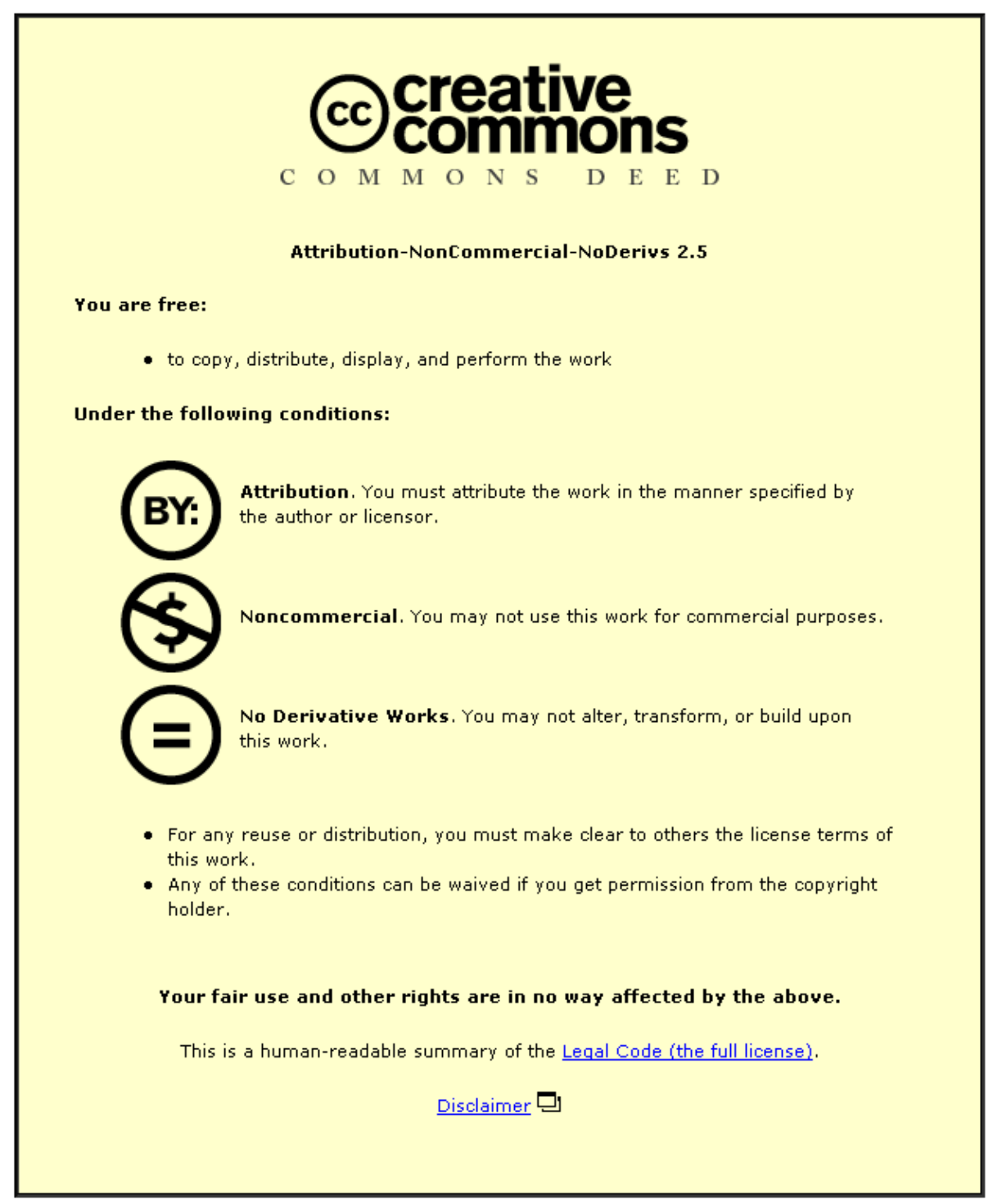

For the full text of this licence, please go to: http://creativecommons.org/licenses/by-nc-nd/2.5/ 


\section{Multiparameter flow cytometry for the characterization of human embryonic stem cells (hESC)}

Kathryn Brosnan, Andrew Want, Karen Coopman and Christopher J Hewitt ${ }^{*}$

Centre for Biological Engineering, Department of Chemical Engineering, Loughborough University, Leicestershire, LE11 3TU, UK

*Author for correspondence. (Phone: +44-1509-222506; Fax: +44-1509-223923; E-mail: c.j.hewitt@lboro.ac.uk)

Keywords: human embryonic stem cells; isotype control; multiparameter flow cytometry; SSEA 4; Tra-1-60; SSEA 1 


\begin{abstract}
Using multiparameter staining methods and flow cytomeyry to investigate the pluripotency of HUES7 human embryonic stem cell cultures it was found that the multidimensional approach of marker co-expression allowed the different cell populations to be easily identified and demonstrated cross reactivity between the SSEA 4 and SSEA 1 antibodies, resulting in a substantial false positive SSEA 1 population. It is the accepted norm to apply control gates at a 95\% confidence level of the isotype control, however this study found that adjusting the control gate to a 99\% confidence level significantly reduced the effect of this cross reactivity. Though conversely, this gating shift also decreased the positive marker expression of SSEA 4 and Tra-1-60, indicating that there is a need for strongly expressing markers coupled with increased optimization of fluorophore/antibody combinations before a gating strategy of 99\% can be implemented on a more routine basis.
\end{abstract}




\section{Introduction}

Flow cytometry is a well-established, analytical technology employed across a wide range of medical and research areas to study the functional and structural properties of a cell. This is often accomplished by targeting protein markers with the application of fluorescently labeled monoclonal antibodies, both within and at the surface of the cytoplasmic membrane. Immunophenotyping is used extensively within hematology, and allows identification of multiple phenotypic and functional markers enabling the comprehensive interrogation of cells on a single cell level (Czechowska et al. 2008; Shapiro 1883). The advantage of flow cytometry is the combination of multiplexed assays; measuring several features of a single cell simultaneously, whilst sampling a statistically significant number of cells ( $\sim 5000)$.

The understanding of the biological and chemical processes that regulate a stem cells' pluripotent and multipotent states would not have developed at the rate, and extent to which, it has, without flow cytometric analysis. Flow cytometry allows cells with any biologically interesting characteristics to be qualified and coupled with the application of fluorescence activated cell sorting (FACS), isolated. This at-line quality control testing and product purification while indispensable at laboratory scale will be critical in bringing clinical therapies to the market (Want et al. 2012).

A number of human embryonic stem cell (hESC) pluripotency associated markers have been documented, both intracellular (e.g. transcription factors NANOG, SOX2 and OCT4 (Chambers et al. 2003; Medvedev et al. 2008; Nichols et al. 1998; Adachi et al. 2010; Fong et al. 2008)) and surface (e.g. glycolipids SSEA 3/4, keratan sulfate antigens Tra-1-60 and Tra- 
1-81 (Draper et al. 2002; Wright and Andrews 2009; International Stem Cell Initiative 2007; Henderson et al. 2002)), however unlike their multipotent counterparts, mesenchymal stem cells (Dominici et al. 2006), no definitive phenotypic marker panel has been agreed upon (International Stem Cell Initiative 2007; Laslett et al. 2003; Carpenter et al. 2004). This is predominantly due to the fact that of the numerous embryonic cell lines that have been established (167 lines approved for use in UK alone (MRC UK Stem Cell Line Registry), for the limited number of these that have been compared at least, the expression levels for the reported pluripotency markers have been shown to be similar but not identical (International Stem Cell Initiative 2007; Carpenter et al. 2004). The contribution of divergent culture techniques in different laboratories to this diversity is debatable (Carpenter et al. 2004; Allegrucci et al. 2005; Allegrucci and Young 2007). Additionally, the lack of knowledge about documented target markers has also hindered the selection of a universal marker panel. This is particularly true for surface markers where for most, their physiological function remains unclear (Henderson et al. 2002; Allegrucci et al. 2005; Allegrucci and Young 2007) especially considering some are not exclusive to hESCs and are expressed on various other cell types (Allegrucci and Young 2007; Barraud et al. 2007; Linju-Yen et al. 2005; Gang et al. 2007). Still, given the potential of non-invasive FACS, surface markers are the ideal standard marker panel candidate. Nevertheless, until such a time that a universal phenotypic marker panel is agreed upon, the current generally accepted minimum criteria for defining pluripotency of a hESC population is by demonstrating the expression of a combination of these markers (Hoffman and Carpenter 2005; Cai et al. 2006), usually with the addition of at least one known differentiation marker as a negative control.

Current hESC literature is awash with flow cytometric data, but the vast majority employ laborious secondary (indirect) antibody methods, where a single fluorophore-conjugated 
antibody is employed to detect all of the markers individually, or single color primary (direct) antibody staining where a fluorophore-conjugated antibody specific for the antigen of interest is applied. These conventional methods while effective in obtaining reliable and reproducible data are somewhat cumbersome and, more critically, information-poor in comparison to the capabilities of modern multiparameter flow cytometry. Multiparameter (a.k.a. multiplex or polychromatic) staining methods, apply a cocktail of fluorophore conjugated antibodies allowing multiple targets to be interrogated simultaneously, each indicated by a different fluorescent color. Pioneered in hematology laboratories in the 1980s (De Rossa et al. 2003), integration into stem cell laboratories has been relatively slow compared to other biological disciplines. Multiparameter flow cytometry is cost efficient, time saving and more robust, while requiring less sample volume than conventional staining methods (Prowse et al. 2009). Most crucially, it allows for the capture of multidimensional data (Jansen et al. 2008) which may otherwise have been left undisclosed. Multiparameter flow cytometry does, however, require a greater degree of understanding of the properties of fluorescent molecules and a greater variety of controls to ensure proper interpretation of data. This, in combination with limited availability of fluorophore-conjugated antibodies and the larger amount of postacquisition analysis has retarded the progression of multiparameter flow cytometry into stem cell research. These challenges are diminished however, by the ability of multiparameter flow cytometry to produce more information-rich datasets with the possibility of observing interactions between markers within a single cell. Currently, only a handful of stem cell focused publications (International Stem Cell Initiative 2007; Carpenter et al. 2004; Henderson et al. 2002; Gang et al. 2007; De Rossa et al. 2003; Prowse et al. 2009; Pruszak et al. 2007; Ramirez et al. 2011) have demonstrated the benefits of this technique but given the strength of the data these have presented, it is predicted that this number will continue to rise. 
Here relatively simple three color multiparameter flow cytometry was employed to investigate the pluripotency of HUES7 hESC cultures. Three extracellular markers were chosen, due to their widespread use within hESC research SSEA 4, Tra-1-60 and SSEA 1. SSEA 1 which has been shown previously to be down regulated on pluripotent hESC and up regulated upon differentiation (Andews et al. 1996; Thomson et al. 1998) was included as a negative control. The main objective of this study was to illustrate the strength of multiparameter flow cytometry methods within stem cell research and how the acquired data can be exploited beyond the scope of the more conventional single color staining methods.

\section{Materials and Methods}

HUES7 cells were cultured feeder free on Matrigel $^{\mathrm{TM}}$ basement matrix ((BD Biosciences) Thomas et al. 2009). Monolayer cultures were maintained in $5 \% \mathrm{CO}_{2} 37^{\circ} \mathrm{C}$ incubators between passages 24 and 36. Cells were passaged using 0.05\% Trypsin/EDTA (Sigma Aldrich) for a 1 minute $37^{\circ} \mathrm{C}$ incubation followed by centrifugation for 5 minutes at $100 \mathrm{~g}$.

All assay reagents and antibody conjugates were supplied as part of a surface antigen kit, FlowCellect Human ESC (Tra-1-60) Surface Marker Characterization Kit (Merck Millipore, Darmstadt, Germany). Briefly, single cell suspensions were prepared in wash buffer at a cell concentration of $1 \times 10^{6} \mathrm{cell} / \mathrm{ml}$. $250 \mu \mathrm{l}$ cell suspension was transferred to each test sample tube before centrifugation at $600 \mathrm{~g}$ for 3 minutes. Cells were resuspended in $500 \mu l$ assay buffer and the centrifugation cycle repeated. After the supernatant was aspirated to waste, cells were resuspended in $100 \mu \mathrm{l}$ of assay buffer. Antibody (Tra-1-60-FITC, SSEA 4 -PE and SSEA 1PE/CY5) and negative control conjugates (IgM-FITC, IgG3-PE and IgM-PE/CY5) were applied (5 5 l per test) before being placed in a light proof container at $2-8^{\circ} \mathrm{C}$ for 1 hour. After incubation $400 \mu \mathrm{l}$ of assay buffer was added and test samples were centrifuged as before. Cells 
were resuspended in a final volume of $500 \mu \mathrm{l}$ assay buffer and analyzed. Preliminary studies indicated that fixation of the cells had no impact on the assay (data not shown) so this step was omitted.

All data were collected using a Guava easyCyte 8HT (equipped with 488 and $640 \mathrm{~nm}$ lasers); post-acquisition analysis was performed using FlowJo (v.7.6.5). Compensation adjustments were carried out at the time of analysis using Incyte ${ }^{\mathrm{TM}}$ acquisition software (v.2.2.2) on the analyzer. During post-acquisition analysis all compensation parameters were verified using the FlowJo ${ }^{\mathrm{TM}}$ compensation tool. A minimum of 5000 gated events per sample was collected.

Throughout the study, cells were periodically karyotyped using standard G-banding of 30 metaphase spreads at the Centre of Medical Genetics, Nottingham, UK. The samples were prepared according to the method described by Thomas et al. (2009).

\section{Results}

The multiparameter assay was conducted on 4 different HUES7 cultures, each at a different passage number; only two assays were subsequent passages of the same culture (Experiment 1 at p34 and Experiment 2 at p36 culture). Cells were found to be karyotypically normal with a minimum of 28/30 nuclei analyzed having 46XY with no increase in abnormalities reported. Also, morphology of the cultures was consistent with pluripotent cells grown in monolayer. The expression levels of the extracellular markers (Figure 1) were indicative of a predominantly pluripotent culture, with each test sample strongly expressing SSEA 4 ( $\geq 96 \%)$ and, while Tra-1-60 was not as strongly expressed, the proportions shown here ( $\geq 60 \%)$ were similar to those reported elsewhere (Draper et al. 2002; Henderson et al. 2002). Figure 1(i) 
clearly demonstrates the power of the multiparameter approach allowing for the quantification of the cell subpopulations that coexpress both positive target markers (SSEA 4 and Tra-1-60). Notably, almost all Tra-1-60 positive cells were SSEA-4 positive. Figure 1(ii) shows similar data expressing SSEA 4 against the negative marker expression SSEA 1, again the use of quadrants allowing the heterogeneous population to be clearly deciphered. The representative dot plot in Figure 1(ii) shows that approximately 15\% of the cell population was expressing SSEA 1 however it was the positioning of this sub population on the SSEA 4 axis that was interesting, because it seemed that the SSEA 1 positive population (median 13.3) was also emitting the strongest SSEA 4 intensity (median 421). On further analysis it was discovered that this was not an isolated event and was consistent throughout each test sample. This was particularly unexpected as it has previously been shown that upon differentiation, SSEA 4 is one of the first markers to be down regulated (International Stem Cell Initiative 2009; Liang et al. 2010).

To explore this observation, the positive SSEA 1 population was backgated on to the SSEA 4 Tra-1-60 dot plot (seen previously Figure 1(i)) to investigate where and how this sub population was distributed among the positive marker population. It was revealed that the SSEA 1 positive (SSEA $1^{\text {+ve }}$ ) population was preferentially distributed high in the double positive quadrant (Figure 2A). The scale of this preferential distribution cluster can be seen for each experiment in Figure 2B where the SSEA $1^{\text {+ve }}$ population was isolated within SSEA 4 Tra-1-60 quadrant gates to attain the percentage distribution.

Figure 2B indicates that the SSEA $1^{+\mathbf{v e}}$ population is positioned at the upper limit SSEA $4^{+\mathbf{v e}}$ intensity. This combined with the low SSEA $1^{+\mathbf{v e}}$ fluorescence intensity, led to the hypothesis that this was the result of cross reactivity between the two glycolipid epitopes and not a true 
SSEA $1^{+\mathrm{ve}}$ population. To test this the isotype control gate was expanded from $95 \%$ to $99 \%$. (Figure 3A). The 4\% adjustment had a significant effect, almost totally eradicating the SSEA $1^{\text {+ve }}$ population, which can be seen when comparing Q6 from Figure 1(iv) with Q6 in Figure 3A(iv). This comparison can be seen even more clearly in Figure 3B which illustrates an example of the before and after backgated dot plot, where the SSEA $1^{+\mathbf{v e}}$ population was reduced from $15.4 \%$ to $2.9 \%$.

Conversely, while expanding the gates reduced the SSEA $1^{+\mathrm{ve}}$ population, the gating shift also reduced the positive population of the other two markers (SSEA $4^{+\mathbf{v e}}$ and Tra-1-60 ${ }^{+\mathbf{v e}}$; Table 1). The decrease in the SSEA $4^{+v e}$ was negligible with the majority of test samples retaining expression $>95 \%$, however Tra-1-60 expression, which in comparison was already relatively low, was considerably reduced with the shift. With expression levels lower than $<45 \%$ the 99\% gate shift has inadvertently disqualified Tra-1-60 as a suitable hESC pluripotency marker for this cell line. To make such a conclusive assumption is beyond the scope of this work and will require a much more in depth study. However it is noteworthy that, when running successive passages (Exp. 1 and Exp. 2), a marked decrease in Tra-1-60 expression was observed over the 6 day culture period, shown in Table 1 . Admittedly, SSEA 1 expression was also significantly decreased during this culture period although the high SSEA $1^{\text {+ve }}$ population seen in Exp. 1 could be attributed to the aforementioned cross reactivity as on average it was reduced from $36 \%$ to $<3 \%$ when the isotype gates were shifted to $99 \%$. SSEA 4 expression was not affected however, and remained constant $>95 \%$ during this period, leading to uncertainties with regard Tra-1-60 expression stability and by extension, further question the suitability of this marker in the panel. 


\section{Discussion}

Multiparameter flow cytometry offers an enormous opportunity to greatly improve the quality and quantity of available data acquired from stem cell analysis. In this present study hESC cultures were investigated for expression of known pluripotency surface markers using a simple 3 color assay. The benefits compared to more conventional secondary or single color primary staining protocols were evident almost immediately. It was calculated that per multiparameter experiment where 8 tubes (1 isotype control, 3 compensation controls and 4 multicolor test samples) were prepared, at least 15 tubes (3 isotype controls and 12 one color test samples) would be required to obtain the same level of repeatability if using conventional methods. This method instantly reduced preparation times, sample size requirements and costs. The inclusion of compensation controls in these initial assay development experiments meant significant savings of antibody volumes were not achieved. However, it was found that the compensation parameters for these experiments was very consistent with only very slight inter-assay adjustment being required (+/- $0.06<3 \%$; data not shown) suggesting perhaps that once a stable protocol has been established, a single run of compensation controls could be used for future experiments. This is particularly true considering any inter assay variation could be corrected using post-acquisition analysis software. Removing these controls from some experiments at least, would decrease operator workload by $75 \%$ per experiment over conventional methods not to mention the increased cost efficiency.

Furthermore, the capacity of additional data output when using multiparameter flow cytometry was enormously beneficial. The multidimensional aspect of marker co-expression was most useful in deciphering the different cell populations and demonstrated that there may be some cross reactivity between the SSEA 4 and SSEA 1 epitopes. This was an unexpected discovery and one that would have been impossible to deduce from conventional staining methods. After a comprehensive review of the recent publications that have reported 
multiparameter flow cytometry methods, surprisingly few have employed SSEA 1 as a negative marker, despite its frequent use in publications that applied conventional staining techniques. As a consequence, similar evidence of this potential cross reactivity does not seem to have been reported, though Strain et al. (2009) did report finding staining in markers with $\leq 10 \%$ of cells above the isotype threshold was most often due to nonspecific binding, and additionally recommended increasing the isotype gates to ensure such events were gated out. The populations measured by flow cytometry can be approximately modeled by a normal distribution: this means that confidence intervals can be utilized that encompass a given proportion of the population. Gating the negative isotype control at a $95 \%$ confidence level literally applies a vertical delimiter defining any population to the left of this point as negative with 95\% probability. Similarly, to the right is deemed a positive population. Current literature is replete with articles where the data has been gated at $95 \%$ of the negative control however this study shows sufficient evidence that this is inadvisable, especially when the implication of such false positives in cells destined for the therapeutic market is considered, some of the samples investigated in this study presented with SSEA $1^{\text {+ve }}$ population of up to $35 \%$, potentially leading to massive product and therefore potential financial losses. On the other hand, if the isotype gates were to be shifted to $99 \%$, then to ensure the utmost confidence in the data, there is a need for strongly expressing markers coupled with increased optimization of fluorophore antibody combinations. Otherwise, there is the risk that target populations will be gated out, again potentially leading to marked financial losses. The consequence of this can be seen in the Tra-1-60 marker expression which was effectively gated out when the isotype gate was increased to $99 \%$. The average level of positive expression seen in this study (>60\%) when gated at $95 \%$ of the isotype control are in line with values reported elsewhere in the literature (Draper et al. 2002; Henderson et al. 2002). However more interestingly, it has been shown that Tra-1-60 expression is particularly 
sensitive to the cell culture conditions (Schinzel et al. 2011) and demonstrated how, by using different culture platforms, the Tra-1-60 expression could be increased or decreased accordingly. This in mind, it is difficult not to consider the possibility that under different culture conditions the recorded loss of expression between passages may have been greatly reduced if not totally eradicated and similarly the gate shift to $99 \%$ may not have been so detrimental to the marker expression in general. This paper lends weight to the opinions of Allegrucci and Young (2007) and the International Stem Cell Initiative (2007), that the regulation and standardization of human embryonic culture conditions among research laboratories could be the first steps required to limit expression marker variation in embryonic cell lines. Perhaps also by extension the first steps towards defining a universal phenotypic marker panel for human embryonic stem cells.

Defining and fully understanding the characterization of pluripotent stem cells remains a major challenge in stem cell biology. Nevertheless, the considerable progress that has been documented to date strongly suggests that this is not an insurmountable task and with time this goal will be achieved. However for this to materialize, it will be imperative that researchers fully exploit current technologies and laboratory protocols to maximize the depth of all available data. Multiparameter flow cytometry is a powerful cell characterization technique that maximizes the capture of significantly more data than conventional flow cytometry methods. This technique has a multitude of benefits to offer current and future stem cell research with available data increasing geometrically with the addition of each parameter (Preffer and Dombkowski 2009). It promises practically limitless potential, with considerable scope remaining for the introduction of new more advanced antibody conjugates to address the fundamental questions that are being raised as the regulatory establishment that controls pluripotent cell states is further elucidated. The application of multiparameter flow cytometry 
in stem cell research is still in its infancy but recent publications (International Stem Cell Initiative 2007; Carpenter et al. 2004; Gang et al. 2007; De Rosa et al. 2003; Prowse et al. 2009; Pruszak et al. 2007; Ramirez et al. 2011) suggest this technique is actively being incorporated into stem cell laboratories worldwide, representing hopefully the first important steps towards ensuring high resolution data-rich experiments become the accepted norm.

\section{Acknowledgements}

This work was funded as part of the Biotechnology and Biological Sciences Research Council (BBSRC; UK) Bioprocessing Research Industries Club (BRIC). We thank Nigel Smith, Dept. of Cytogenetics, Centre of Medical Genetics, Nottingham, UK for the karyotype analysis. We also greatly appreciate the assistance of Lorraine Young and Chris Denning, University of Nottingham, UK for providing the cells used and training in cell culture.

\section{References}

Adachi K, Hirofumi S, Yasuda S, Nakatsuji N, Kawase E (2010) Role of SOX2 in maintaining pluripotency of human embryonic stem cells. Genes to Cells. 15: 455-469

Allegrucci C, Denning CN, Burridge P, Steele W, Sinclair KD, Young LE (2005) Human embryonic stem cells as a model for nutritional programming: an evaluation. Reprod Toxicol 20: $353-367$.

Allegrucci C, Young LE (2007) Differences between human embryonic stem cell lines. Hum. Reprod. Update 13: 103-120. 
Barraud P, Stott S, MØllgard K, Parmar M, BjÖrklund A (2007) In vitro characterisation of a human neural progenitor cell coexpressing SSEA 4 and CD133. J. Neurosci. Res. 85: 250259.

Andrews PW, Casper J, Damjanov I, Duggan-Keen M, Giwercman A, Hata J, Keitz A, Looijenga LHJ, Millian JL, Oosterhuis JW, Pera M, Sawada M, Schmoll HJ, Skakkebaek NE, Putten W, Stern P (1996) Comparative analysis of cell surface antigens expressed by cell lines derived from human germ cell tumours. Int. J. Cancer. 66: 806-8

Brimble SN, Sherrer ES, Uhl EW, Wang E, Kelly S, Merrill AH, Robins AJ, Schulz TC (2007) The cell surface glycosphingolipids SSEA-3 and SSEA-4 are not essential for human ESC pluripotency. Stem Cells. 25: 54-62.

Cai J, Chen J, Liu Y, Miura T, Luo Y, Loring JF, Freed WJ, Rao MS, Zeng X (2006) Assessing self-renewal and differentiation in hESC lines. Stem Cells. 24: 516-530.

Carpenter MK, Rosler ES, Fisk GJ, Brandenberger R, Ares X, Miura T, Lucero M, Rao MS (2004) Properties of four human embryonic stem cell lines maintained in a feeder free culture system. Dev. Dyn. 229: 243-258.

Chambers I, Colby D, Robertson M, Nichols J, Lee S, Tweedie S, Smith A (2003) Functional expression cloning of Nanog, a pluripotency sustaining factor in embryonic stem cells. Cell. 113: 643-655. 
Czechowska K, Johnson DR, van der Meer JR. (2008) Use of flow cytometry for single cell analysis in environmental microbiology. Curr. Opin. Microbiol. 11: 205-212.

De Rosa SC, Brenchley JM, Roederer M (2003) Beyond six colors: A new era in flow cytometry. Nat. Med. 9: 112-117.

Dominici M, Le Blanc K, Mueller I, Slaper-Cortenbach I, Marini FC, Krause DS, Deans RJ, Keating A, Prockop DJ, Horwitz EM (2006) Minimal criteria for defining multipotent mesenchymal stromal cells. The international society for cellular therapy position statement. Cytotherapy. 8: 315-317.

Draper JS, Pigott C, Thomson JA, Andrews PW (2002) Surface antigens of human embryonic stem cells: changes upon differentiation in culture. J. Anat. 200: 249-258.

Fong H, Hohenstein K, Donovan PJ (2008) Regulation of self-renewal and pluripotency by Sox2 in human embryonic stem cells. Stem Cells. 26: 1931-1938.

Gang EJ, Bosnakovski D, Figueiredo CA, Visser JW, Perlingeiro RCR (2007) SSEA 4 identifies mesenchymalstem cells for bone marrow. Stem Cells in Hematology. 109: 17431751.

Henderson JK, Draper JS, Baillie HS, Fishel S, Thomson JA, Moore H, Andrews PW (2002) Pre-implantation human embryos and embryonic stem cells show comparable expression of stage specific embryonic antigens. Stem Cells. 20: 329-337. 
Hoffman LM, Carpenter MK (2005) Characterization and culture of human embryonic stem cells. Nat. Biotechnol. 23: 699-708.

International Stem Cell Initiative (2007) Characterisation of human embryonic stem cell lines by the international stem cell initiative. Nat. Biotechnol. 25: 803-816.

Jansen K, Blimkie D, Furlong J, Hajjar A, Rein-Weston A, Crabtree J, Reikie B, Wilson C, Kollmann T (2008) Polychromatic flow cytometric high-throughput assay to analyze the innate immune response to Toll-like receptor stimulation. J. Immunol. Methods. 336: 183-192

Laslett AL, Filipczyk AA, Pera MF (2003) Characterisation and culture of human embryonic stem cells. Trends Cardiovasc. Med. 13:295-301.

Liang YJ, HH Kuo, CH Lin, YY Chen, BC Yang, YY Cheng, AL Yu, KH Kho and J Yu. (2010). Switching of the core structures of glycosphingolipids from globo- and lacto- to ganglio-series upon human embryonic stem cell differentiation. PNAS 107:52:22564-22569.

Linju-Yen B, Huang HI, Chien CC, Jui HY, Ko BS, Yao M, Shun CT, Yen ML, Lee MC, Chen YC (2005) Isolation of multi-potent cells from human term placenta. Stem Cells 23: 3-9.

Medvedev SP, Shevchenko AI, Mazurok NA, Zakian SM (2008) OCT4 and NANOG are the key genes in the system of pluripotency maintenance in mammalian cells. Russ. J. Genet. 44: 1377-1393. 
MRC, UK Stem Cell Line Registry [Internet], Issued 2008. [Cited 2012 Jun 7]. Available from http://www.mrc.ac.uk/consumption/groups/public/documents/content/mrc003259.pdf

Nichols J, Zevnik B, Anastassiadis K, Niwa H, Klewe-Nebenius D, Chambers I, SchÖler H, Smith A (1998) Formation of pluripotent stem cells in the mammalian embryo depends on the POU transcription factor Oct4. Cell. 95: 379-391.

Prowse ABJ, Wilson J, Osborne GW, Gray PP, Wolvetang EJ (2009) Multi-plexed staining of live human embryonic stem cells for flow cytometry analysis of pluripotency markers. Stem Cells Dev. 18: 1135-1140.

Preffer F and Dombkowski D (2009) Advances in multiparameter flow cytometry technology: Applications in stem cell research. Cytom. Part B-Clin. Cy. 76B :295-314.

Pruszak J, Sonntag KC, Aung MH, Sanchez-Pernaute R, Isacson O (2007) Markers and methods for cell sorting of human embryonic stem cell derived neural cell populations. Stem Cells. 25:9:2257-2268.

Ramirez JM, Gerbal-Chaloin S, Milhavet O, Bai Q, Becker F, Assou S, Lemaître JM, Hamamah S, De Vos J (2011) Benchmarking human pluripotent stem cell markers during differentiation into the three germ layers unveils a striking heterogeneity: All markers are not equal. Stem Cells. 29: 1469-1474. 
Schinzel RT, Ahfeldt T, Lau FH, Lau YK, Cowley A, Shen T, Peters D, Lum DH, Cowan CA (2011) Efficient Culturing and Genetic Manipulation of Human Pluripotent Stem Cells. PLoS One. 6: 12:1-6.

Shapiro HM (1983) Multistation multiparameter flow cytometry: A Critical Review and Rationale. Cytometry. 3: 227-242.

Strain E, Hahne F, Brinkman RR, Haaland P (2009) Analysis of high throughput flow cytometry data using platecore. Adv. Bioinformatics. 356141: 1-10.

Thomas RJ, Anderson D, Chandra A, Smith NM, Young LE, Williams D, Denning C (2009) Automated, scalable culture of human embryonic stem cells in feeder-free conditions. Biotechnol. Bioeng. 102: 1636-1644.

Thomson JA, Itskovitz-Eldor J, Shapiro SS, Waknitz MA, Swiergiel JJ, Marshall VS, Jones JM (1998) Embryonic stem cell lines derived from human blastocysts. Science 282: 1145 1147.

Want AJ, Nienow AW, Hewitt CJ, Coopman K (2012) Large scale expansion and exploitation of pluripotent stem cells for regenerative medicine purposes: beyond the T flask. Regen. Med. 7: 71-84.

Wright AJ, Andrews PW (2009) Surface marker antigens in the characterization of human embryonic stem cells. Stem Cell Research. 3: 3-11. 


\section{Figure and Table Legends}

Figure 1 - Cell Distribution at 95\% Isotype Control Gate (i) and (ii) representative dot plots for the three markers, (i) SSEA 4/PE against Tra-1-60/FITC and (ii) SSEA 4/PE against SSEA 1/ PE-CY5. Each dot plot is flanked by two histograms highlighting the positioning of the quadrant boundaries corresponding to 95\% of the isotype control. (iii) and (iv) bar charts are used to represent a specific quadrant on the density plot, with each bar showing the mean of the samples within a single experiment (error bars are calculated from the standard error). $\mathrm{n} \geq 3$ in all cases.

Figure 2 - SSEA $1^{\text {+ve }}$ Population Distribution (A) The isolated positive SSEA 1 population, shown here in the single color histogram was backgated onto the SSEA 4 Tra-1-60 dot plot. Backgating illustrated SSEA $1^{\text {+ve }}$ population preferentially distributed high in the double positive quadrant Q2. (red black dot plot, where the red is the SSEA 1 positive population). Note slight increase in positive percentage from $15.2 \%$ on figure 1 (ii) to $18.9 \%$ on histogram due to fact quadrant dot plot is gated at 95\% of two colors and not just single color as in the case of the histogram. (B) The positive SSEA 1 population was isolated within the SSEA 4 Tra-1-60 quadrant gates to identify the percentage distribution of this daughter population for each sample. The percentage distribution is displayed on a bar chart next to the parent SSEA 4 Tra-1-60 population distribution.

Figure 3 - Cell Distribution at 99\% Isotype Control Gate (A) (i) and (ii) show representative dot plots for the three markers, (i) SSEA 4/PE against Tra-1-60/FITC and (ii) SSEA 4/PE against SSEA 1/ PE-CY5. Each dot plot is flanked by two histograms highlighting the positioning of the quadrant boundaries corresponding to $99 \%$ of the isotype control. (iii) and (iv) bar charts are used to represent a specific quadrant on the density plot, with each bar showing the mean of 
the samples within a single experiment (error bars are calculated from the standard error). $\mathrm{n} \geq$ 3 in all cases. (B) Illustrates a representative backgated dot plot before and after the gate shift. (i) shows the distribution of the SSEA $1^{\text {+ve }}$ population at $95 \%$ of the isotype control on the left (shown previously in Figure 2) and (ii) on the right shows same population after the isotype control gate has been increased to $99 \%$.

Table 1. Expression (\%) of surface markers recorded at 95\% and 99\% gating. The column immediately following the marker title column $\left(2^{\text {nd }}\right.$ from left) highlights the single color expression levels for each marker. A loss of Tra- $1-60^{+v e}$ expression was observed between subsequent cultures (76.5 - 55.0\%). Cells were in culture 6 days between analyses. Multiparameter marker co-expression can be read by cross referencing the marker title (column 1) against the markers titled within the multiparameter column. Values given are the mean of the samples within a single experiment ( \pm are calculated from the standard error) for each run, $\mathrm{n} \geq 3$ in all cases. 
Table 1

\begin{tabular}{|c|c|c|c|c|c|c|c|c|c|c|c|}
\hline \multicolumn{11}{|c|}{ \% Expression } & \\
\hline & & \multicolumn{2}{|c|}{$\begin{array}{c}\text { Single Parameter } \\
\text { Data }\end{array}$} & \multicolumn{8}{|c|}{ Multiparameter Data } \\
\hline & & \multirow{3}{*}{$95 \%$} & \multirow{3}{*}{$99 \%$} & \multicolumn{4}{|c|}{ SSEA 4} & \multicolumn{4}{|c|}{ Tra-1-60 } \\
\hline & & & & $95 \%$ & $99 \%$ & $95 \%$ & $99 \%$ & $95 \%$ & $99 \%$ & $95 \%$ & $99 \%$ \\
\hline & & & & \multicolumn{2}{|c|}{ +ve } & \multicolumn{2}{|c|}{-ve } & \multicolumn{2}{|c|}{$+v e$} & \multicolumn{2}{|c|}{-ve } \\
\hline \multirow{6}{*}{$\begin{array}{l}\operatorname{Exp} 1 \\
(n=3)\end{array}$} & SSEA 4 +ve & $97.5 \pm 1.5$ & $81.9 \pm 10.7$ & & & & & & & & \\
\hline & SSEA 4 -ve & $3.2 \pm 1.2$ & $18.1 \pm 10.7$ & & & & & & & & \\
\hline & Tra-1-60 +ve & $75.6 \pm 4.0$ & $42.1 \pm 5.2$ & $73.1 \pm 3.3$ & $34.4 \pm 0.6$ & $2.5 \pm 0.1$ & $7.8 \pm 5.7$ & & & & \\
\hline & Tra-1-60 -ve & $25.3 \pm 4.4$ & $2.6 \pm 1.2$ & $24.6 \pm 4.8$ & $47.5 \pm 10.2$ & $0.7 \pm 0.4$ & $10.3 \pm 5.1$ & & & & \\
\hline & SSEA 1 +ve & $36.1 \pm 9.0$ & $2.6 \pm 1.2$ & $35.9 \pm 9.1$ & $2.5 \pm 1.3$ & $0.2 \pm 0.1$ & $0.1 \pm 0.0$ & $31.8 \pm 4.9$ & $4.8 \pm 1.9$ & $10.8 \pm 4.4$ & $1.8 \pm 1.4$ \\
\hline & SSEA 1 -ve & $63.8 \pm 9.0$ & $97.4 \pm 1.2$ & $61.6 \pm 8.5$ & $80.2 \pm 9.6$ & $2.28 \pm 1.6$ & $17.2 \pm 10.3$ & $33.0 \pm 6.9$ & $43.2 \pm 6.2$ & $24.3 \pm 4.4$ & $50.4 \pm 4.6$ \\
\hline \multirow{6}{*}{$\begin{array}{l}\operatorname{Exp} 2 \\
(n=4)\end{array}$} & SSEA 4 +ve & $98.5 \pm 0.1$ & $96.3 \pm 0.3$ & & & & & & & & \\
\hline & SSEA 4 -ve & $1.5 \pm 0.1$ & $3.7 \pm 0.3$ & & & & & & & & \\
\hline & Tra-1-60 +ve & $55.0 \pm 1.8$ & $25.9 \pm 1.4$ & $54.7 \pm 1.8$ & $25.6 \pm 1.4$ & $0.2 \pm 0.1$ & $0.3 \pm 0.1$ & & & & \\
\hline & Tra-1-60 -ve & $45.0 \pm 1.8$ & $74.1 \pm 1.4$ & $43.8 \pm 1.9$ & $70.7 \pm 1.6$ & $1.2 \pm 0.1$ & $3.4 \pm 0.2$ & & & & \\
\hline & SSEA 1 +ve & $6.9 \pm 0.2$ & $1.3 \pm 0.1$ & $6.7 \pm 0.24$ & $1.2 \pm 0.1$ & $0.2 \pm 0.0$ & $0.1 \pm 0.0$ & $5.8 \pm 0.3$ & $0.9 \pm 0.1$ & $0.64 \pm 0.0$ & $0.3 \pm 0.0$ \\
\hline & SSEA 1 -ve & $93.0 \pm 0.2$ & $98.7 \pm 0.1$ & $92.1 \pm 0.2$ & $95.8 \pm 0.2$ & $0.9 \pm 0.1$ & $2.9 \pm 0.3$ & $46.5 \pm 1.9$ & $22.9 \pm 1.4$ & $47.0 \pm 1.8$ & $75.9 \pm 1.4$ \\
\hline \multirow{6}{*}{$\begin{array}{l}\operatorname{Exp} 3 \\
(n=4)\end{array}$} & SSEA 4 +ve & $99.8 \pm 0.1$ & $98.2 \pm 0.2$ & & & & & & & & \\
\hline & SSEA 4 -ve & $0.2 \pm 0.0$ & $1.7 \pm 0.2$ & & & & & & & & \\
\hline & Tra-1-60 +ve & $79.2 \pm 0.9$ & $42.3 \pm 1.5$ & $79.2 \pm 0.9$ & $42.2 \pm 1.5$ & $0.1 \pm 0.0$ & $0.1 \pm 0.0$ & & & & \\
\hline & Tra-1-60 -ve & $20.8 \pm 0.9$ & $57.7 \pm 1.5$ & $20.7 \pm 0.9$ & $56.1 \pm 1.3$ & $0.2 \pm 0.0$ & $1.6 \pm 0.2$ & & & & \\
\hline & SSEA $1+\mathbf{v e}$ & $14.6 \pm 0.6$ & $2.7 \pm 0.1$ & $14.6 \pm 0.6$ & $1.2 \pm 0.1$ & $0.0 \pm 0.0$ & $0.0 \pm 0.0$ & $8.91 \pm 0.2$ & $2.1 \pm 0.1$ & $0.74 \pm 0.1$ & $0.8 \pm 0.1$ \\
\hline & SSEA 1 -ve & $85.4 \pm 0.6$ & $97.3 \pm 0.1$ & $85.2 \pm 0.6$ & $95.8 \pm 0.2$ & $0.2 \pm 0.0$ & $1.6 \pm 0.2$ & $69.1 \pm 1.1$ & $33.9 \pm 1.4$ & $21.1 \pm 0.9$ & $63.3 \pm 1.3$ \\
\hline \multirow{6}{*}{$\begin{array}{c}\text { Exp 4 } \\
(\mathrm{n}=4)\end{array}$} & SSEA 4 +ve & $98.9 \pm 0.1$ & $89.5 \pm 0.5$ & & & & & & & & \\
\hline & SSEA 4 -ve & $1.1 \pm 0.1$ & $10.5 \pm 0.5$ & & & & & & & & \\
\hline & Tra-1-60 +ve & $57.6 \pm 1.4$ & $29.8 \pm 1.5$ & $57.5 \pm 1.4$ & $28.8 \pm 1.4$ & $0.1 \pm 0.0$ & $1.0 \pm 0.1$ & & & & \\
\hline & Tra-1-60 -ve & $42.3 \pm 1.4$ & $70.2 \pm 1.5$ & $41.3 \pm 1.4$ & $60.7 \pm 1.4$ & $1.0 \pm 0.1$ & $9.5 \pm 0.5$ & & & & \\
\hline & SSEA 1 +ve & $17.4 \pm 1.9$ & $1.8 \pm 0.4$ & $17.1 \pm 1.8$ & $1.7 \pm 0.4$ & $0.3 \pm 0.1$ & $0.1 \pm 0.0$ & $11.5 \pm 0.9$ & $1.2 \pm 0.2$ & $7.7 \pm 1.2$ & $0.7 \pm 0.2$ \\
\hline & SSEA 1 -ve & $82.6 \pm 1.9$ & $98.2 \pm 0.4$ & $81.5 \pm 1.8$ & $87.8 \pm 0.5$ & $1.1 \pm 0.1$ & $10.4 \pm 0.5$ & $39.2 \pm 0.6$ & $23.5 \pm 1.5$ & $41.6 \pm 2.8$ & $74.5 \pm 1.3$ \\
\hline
\end{tabular}


Figures

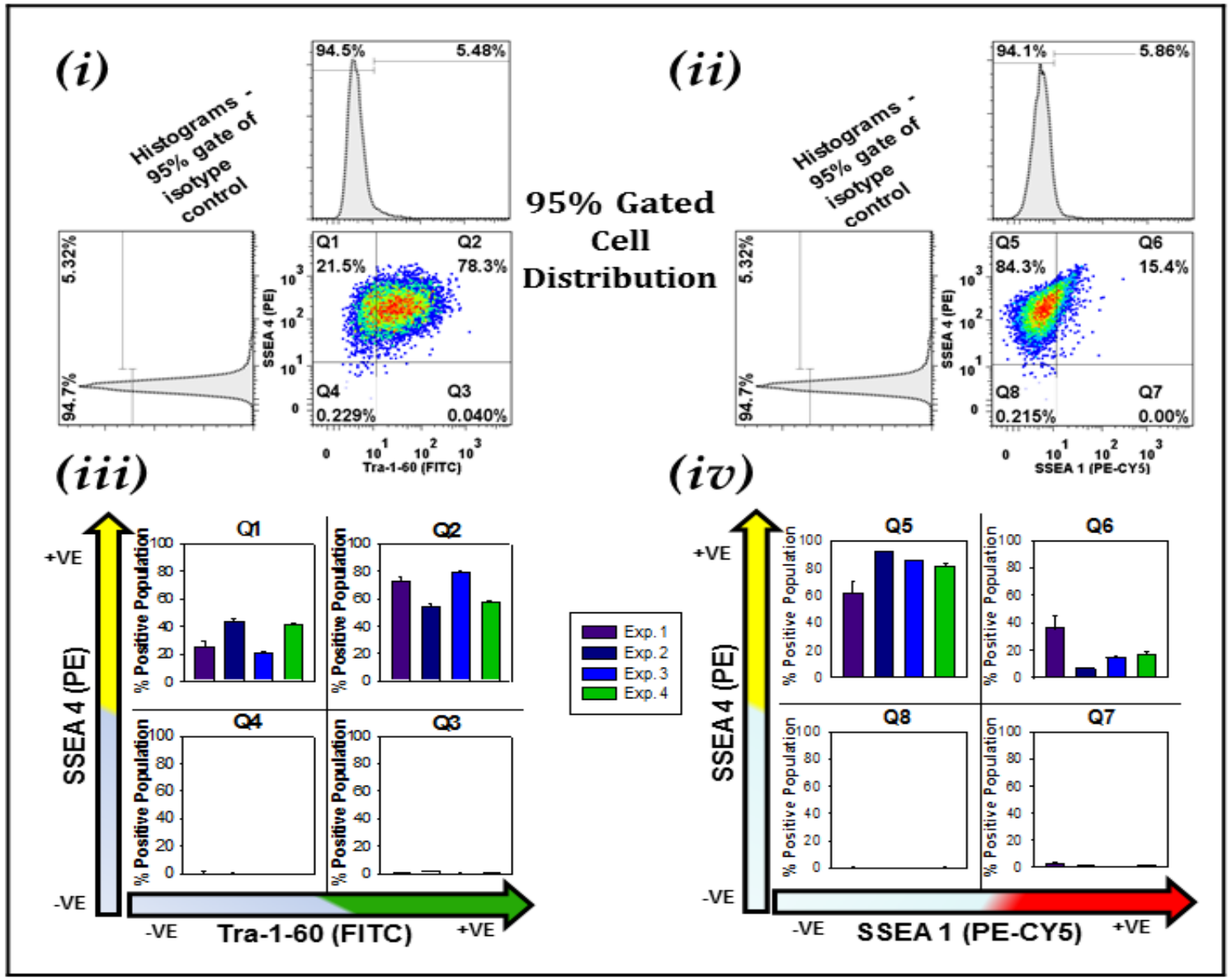

Figure 1 

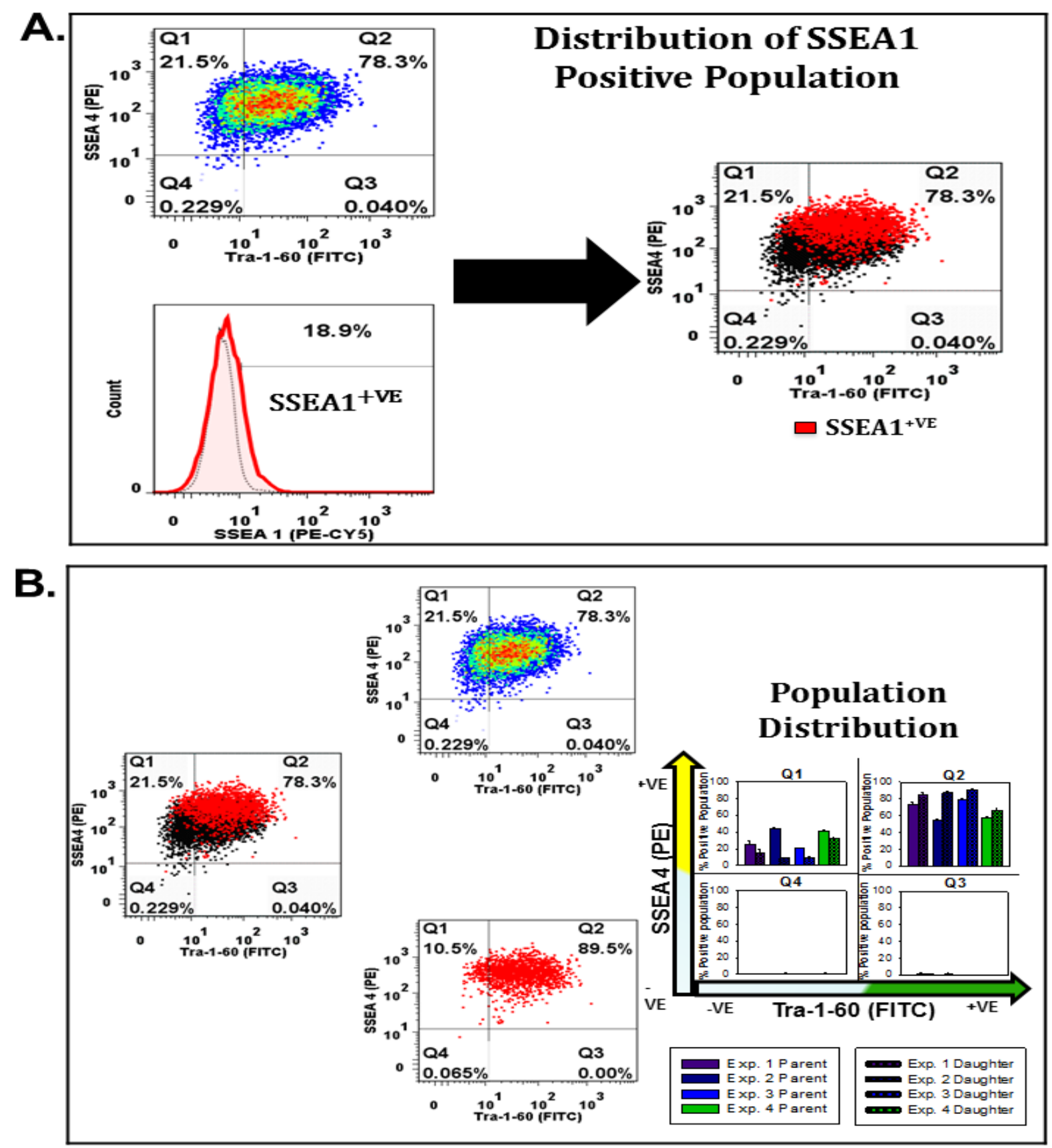

Figure 2 


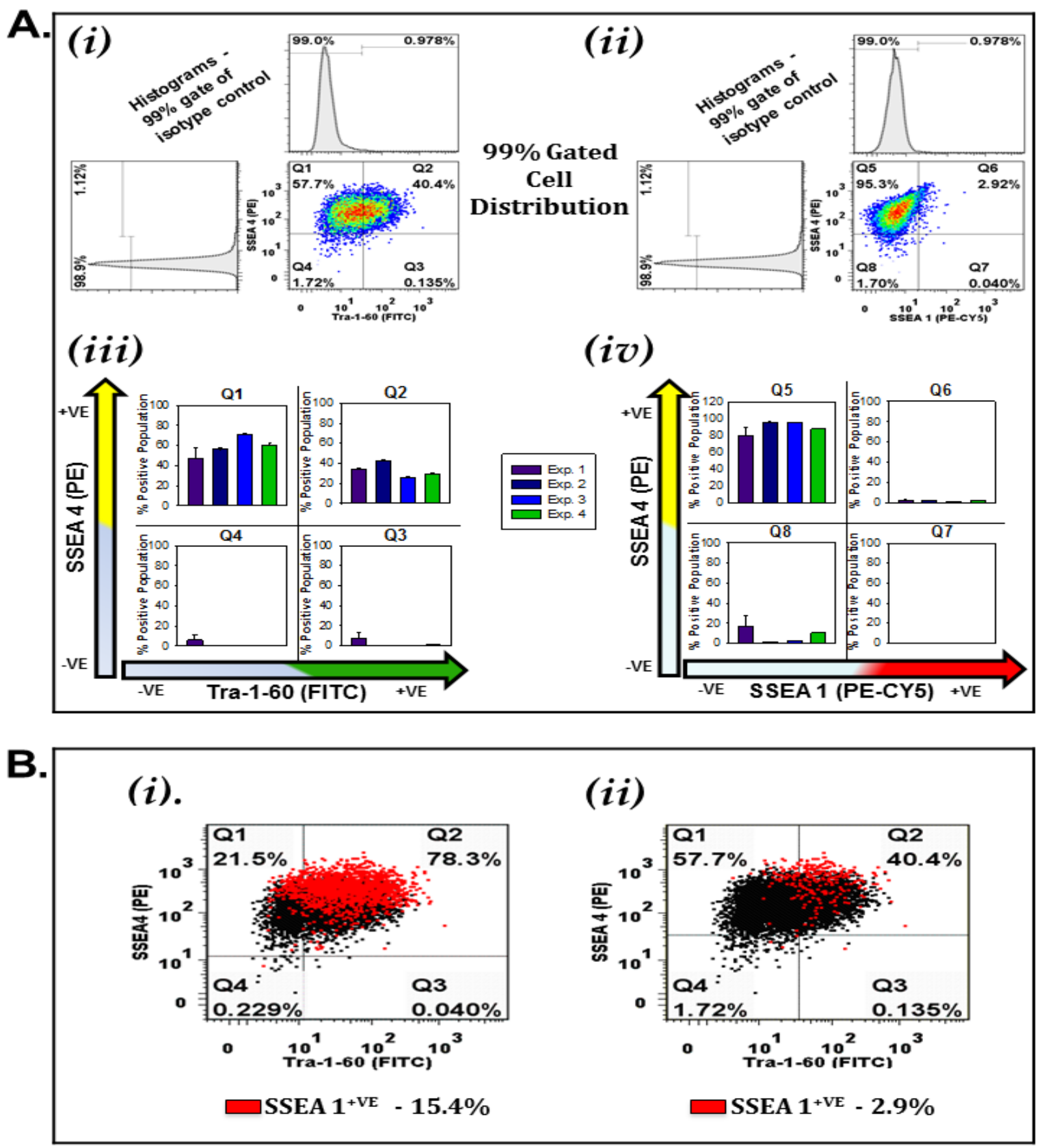

Figure 3 


\section{Supplementary Figures}

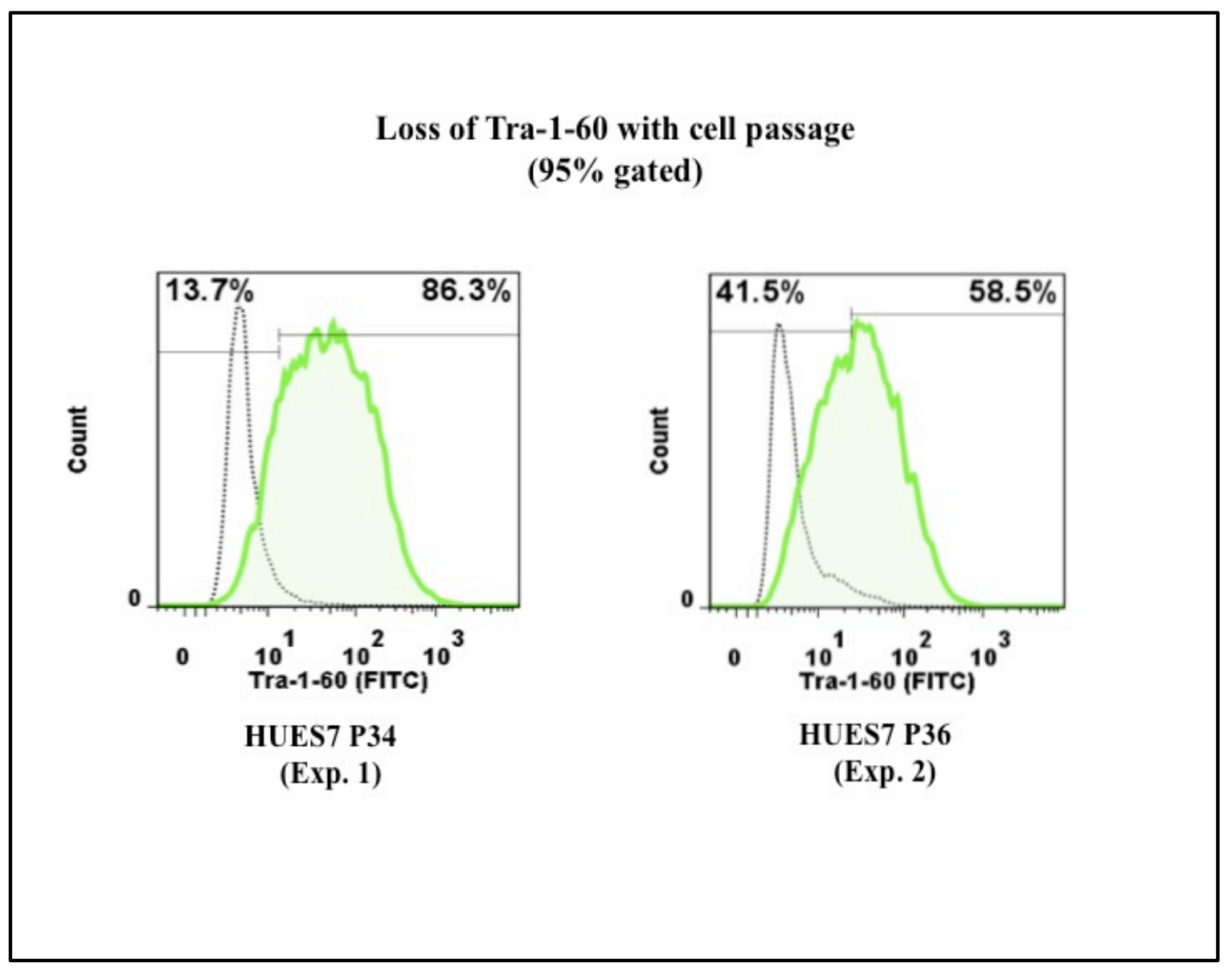

Supplementary Figure 1. Representative single color histograms demonstrating the Tra-1-60 ${ }^{+v e}$ expression of two successive passages, p34 (Exp. 1) and p36 (Exp. 2) where there was a significant reduction in positive expression. Cells were in culture 6 days between analyses. 